University of Rhode Island

DigitalCommons@URI

Open Access Master's Theses

2020

\title{
THE IMPACTS OF HEARING LOSS ON SOCIAL-EMOTIONAL HEALTH
}

Lili Lan Lebrun Visgilio

University of Rhode Island, Ivisgilio@uri.edu

Follow this and additional works at: https://digitalcommons.uri.edu/theses

\section{Recommended Citation}

Visgilio, Lili Lan Lebrun, "THE IMPACTS OF HEARING LOSS ON SOCIAL-EMOTIONAL HEALTH" (2020). Open Access Master's Theses. Paper 1864.

https://digitalcommons.uri.edu/theses/1864

This Thesis is brought to you for free and open access by DigitalCommons@URI. It has been accepted for inclusion in Open Access Master's Theses by an authorized administrator of DigitalCommons@URI. For more information, please contact digitalcommons-group@uri.edu. 
THE IMPACTS OF HEARING LOSS ON SOCIAL-EMOTIONAL HEALTH

BY

LILI LAN LEBRUN VISGILIO

\begin{abstract}
A THESIS SUBMITTED IN PARTIAL FULFILLMENT OF THE
REQUIREMENTS FOR THE DEGREE OF

MASTER OF SCIENCE

IN

HUMAN DEVELOPMENT AND FAMILY STUDIES

DEVELOPMENTAL SCIENCE
\end{abstract}

UNIVERSITY OF RHODE ISLAND

2020 
MASTER OF SCIENCE THESIS

OF

LILI LAN LEBRUN VISGILIO

\author{
APPROVED: \\ Thesis Committee \\ Major Professor Karen McCurdy \\ Sue K. Adams \\ Rachel-Ann Smith \\ Nasser H. Zawia \\ DEAN OF THE GRADUATE SCHOOL
}

UNIVERSITY OF RHODE ISLAND

2020 


\begin{abstract}
According to the World Health Organization, over 900 million people are expected to have disabling hearing loss by 2050. Most studies about hearing loss published thus far have focused on the impacts hearing loss has on adults above the age of 60 . However, this study examines the relationship between hearing loss and social-emotional health in adults between the ages of 21 and 50. Literature describing the impact of hearing loss on the social-emotional health of young and middle aged adults is sparse. This study uses data from the 2011 wave of the National Health Interview Survey (NHIS) obtained via the Inter-University Consortium for Political and Social Research (ICPSR) website. Using individual variables in the study regarding depression, anxiety, exhaustion, and a person's ability to participate in leisure activities, a social-emotional health scale was created by adding the four individual measures. The newly created social-emotional health scale was reliable $(\alpha=0.69)$. To analyze the relationship between social-emotional health and hearing loss, an independent samples t-test was conducted. The results of the t-test were statistically significant $(p<0.001)$ and found that hearing loss is associated with poorer social-emotional health. A linear regression was conducted to identify if demographic variables influenced social-emotional health scores. The results of the linear regression found that even after controlling for significant demographic differences between participants with difficulty hearing and those with typical hearing, social-emotional health is still significantly related to participants' hearing ability $(p<$ 0.001). These results suggest that mental health professionals should be educated about the unique experiences those with hearing loss face.
\end{abstract}




\section{ACKNOWLEDGMENTS}

My thesis would not be possible without the love and encouragement of several people. First and foremost, I would like to thank family and friends, and I would especially like to thank my mom, dad, and Godmother for their endless support.

I would also like to thank my major advisor, Dr. Karen McCurdy, for pushing me to do my best work. The writing process was difficult at times but through her guidance, the "lightbulb moments" I experienced along the way were invaluable. I would also like to thank my departmental committee member, Dr. Sue K. Adams, and my outside committee member, Dr. Rachel-Ann Smith. Your input and expertise have been of the utmost importance. Thank you for joining me on this crazy ride. Additionally, I would like to thank the members of the Human Development faculty and staff especially Dr. Hans St. Eloi-Cadely, Dr. Melanie Brasher, Tracey Maron, M.Ed. and Suzanne Horton. Thank you for being sources of strength during my time at URI and during the thesis writing process.

I would also like to thank MJF and TF for their vulnerability and sharing their hearing loss journey with me. Their stories helped me to become more open about my own struggles and passionate about changing the narrative surrounding hearing loss. Finally, I would like to thank Lizzy Weiss, the creator and producer of the $\mathrm{ABC}$ Family's hit show, Switched At Birth. Thank you for introducing me to Deaf culture, the beauty of American Sign Language (ASL), and showing me that hearing loss can only stop me if I let it.

If you want to go fast, go alone, If you want to go far, go together - African Proverb - Thank you for helping me go far. 


\section{TABLE OF CONTENTS}

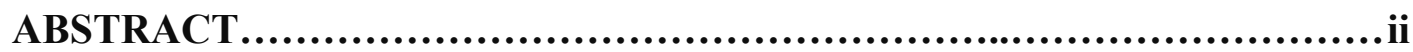

ACKNOWLEDGMENTS...................................................... iii

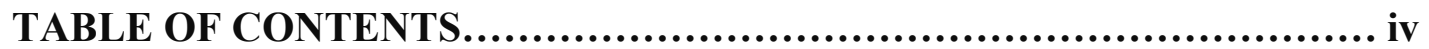

LIST OF TABLES ..........................................................

CHAPTER I...................................................................... 1

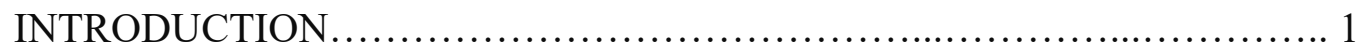

CHAPTER II......................................................................5

REVIEW OF LITERATURE................................................

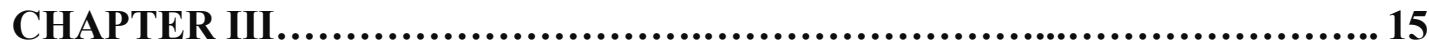

METHODOLOGY .................................................................. 15

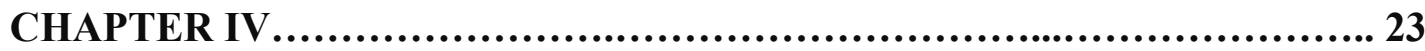

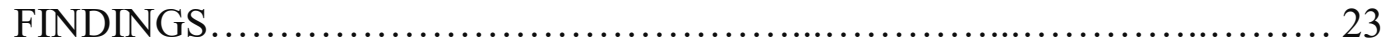

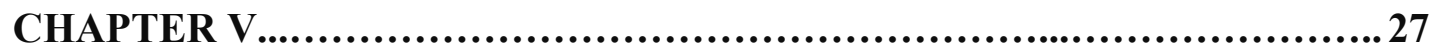

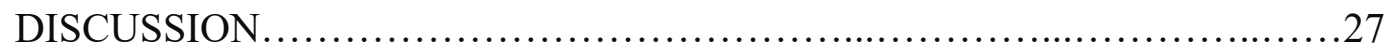

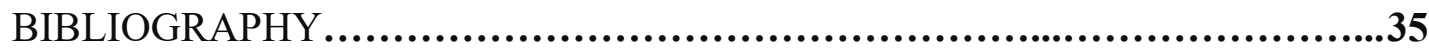




\section{LIST OF TABLES}

TABLE

PAGE

Table 1. Demographics of Participants 21-50 based on Data Present.................17

Table 2. Demographics of Participants 21-50 based on Hearing Ability.............24

Table 3. Independent Samples T-Test based on Hearing Ability......................25

Table 4. Linear Regression of Difficulty Hearing Controlling for Significant

Demographics........................................................... 26 


\section{CHAPTER I}

\section{INTRODUCTION}

Hearing loss is a growing problem that affects millions of people. According to the World Health Organization (WHO) in 2020, approximately 466 million people globally have disabling hearing loss (greater than $40 \mathrm{~dB}$ in the better ear for adults and $30 \mathrm{~dB}$ in the better ear for children). The Global Burden of Disease (GBD) study found hearing loss is the third most common cause for long-term disability (Hasson, Theorell, Bergquist, \& Canlon, 2013). Mild unilateral (single-sided) hearing loss affects $23 \%$ of Americans who are 12 years old and above and 1 in 7 Americans has bilateral (double-sided) hearing loss (Goman \& Lin, 2016). Noise-induced hearing loss is becoming more severe in residents living in cosmopolitan settings compared to residents living in rural (Kumar, Sahu, Basod, \& Patel, 2017). The levels of noise residents between the ages of 21-30 are exposed to living in cosmopolitan areas significantly impacts their hearing compared to their counterparts living in small towns and rural areas (Kumar et al. 2017; Wang et al. 2019).

According to the World Health Organization (WHO) in 2019, untreated hearing loss costs the world $\$ 750$ billion annually. Unlike glasses, using assistive technology such as hearing aids and cochlear implants (CIs) can be stigmatizing and costly. This may deter some people from seeking help when symptoms first appear which limits them from participating in social activities (Blazer \& Tucci, 2018; Powell, Jacobs, Noble, Bush \& Snell-Rood, 2019). The WHO states that if prevention 
strategies, interventions, and tools to address hearing loss were implemented sooner, it would benefit people struggling with hearing loss and would be more cost-effective in the long run.

Many adults between 21 and 50 years old with hearing loss have unhealthy attitudes about their diagnosis and are uneducated about the long-term consequences untreated hearing loss carry (Hunter, 2018; Idstad, Tambs, Aarhus, \& Engdahl, 2019; Kujawa \& Liberman, 2006). Young and middle-aged adults with hearing loss also struggle with stigma related to societal expectations assuming hearing loss only affects older adults (Baldridge \& Kulkarni, 2017). An article in Psychology Today states that many adolescents and young adults have trouble accepting their diagnosis, struggle with stigma, and do not understand the impact long-term noise exposure has on their future (Eberts, 2018; NAHIC, 2014). This demonstrates the importance of research examining young and middle-aged adults with hearing loss.

The theoretical frameworks that may explain unhealthy attitudes and negative effects of hearing loss in young and middle-aged adults are the life-course perspective and social role theory. The life-course perspective indicates how society's expectations influence our development throughout our lives regarding education, family life, and work (Newman \& Newman, 2016). Similar to social role theory, the life-course perspective depends heavily on the "social clock" which indicates where people "should be" in school, higher education, their career, and parenthood. Incorporating the life-course perspective theory in this study is critical and may explain why young and middle-aged adults have a harder time with a hearing loss diagnosis. Since hearing loss is traditionally thought to exclusively affect adults 60 
years and older, this theory may suggest that many young and middle-aged adults may feel ashamed when they are diagnosed with what is considered an "older person's condition" (Amieva, Ouvrard, Meillon, Rullier, \& Dartigues, 2018; Blazer \& Tucci, 2018).

The second theoretical framework used is social role theory which, "provides a way of thinking about the links between personal development and the social environment" (Newman \& Newman, 2016, p. 167). Social role theory explains "age norms," and "age roles" as frameworks for people of different age groups. These concepts set expectations of how a person should behave based on a person's age, occupation, gender, socio-economic status, and ability as well as a baseline of what people should be experiencing during different periods in their lives. Additionally, since hearing loss can happen at any time during a person's life, "abrupt entry into new roles" may explain why adults aged 21-50 experience emotional distress when diagnosed with hearing loss at a younger age.

People often struggle with stigma related to hearing loss (Baldridge \& Kulkarni, 2017). Studies found untreated hearing loss in people between 13 and 70 years old can result in social isolation, cognitive decline, feelings of incompetence, and higher levels of depression in the workplace (Baldridge \& Kulkarni, 2017; Dawes et al., 2015; Stevenson et al., 2017). However, the findings of these quantitative studies are from small, non-nationally representative samples ranging from 40-240 participants (Abbas, Aqeel, Jaffar, Nurunabi, \& Bano, 2019; Kobosko et al. 2018, Palmer, Newsom, \& Rook 2016; Powell et al., 2019). The direct relationship between hearing loss and a person's social-emotional health (depression, social isolation, 
cognitive decline, and self-stigmatization) has been studied extensively for adults aged 60 and above (Amieva et al., 2018, Castiglione et al., 2016; David, Zoizner, \& Werner, 2018; Uchida et al., 2019). However, few studies have researched the relationship between hearing loss and multiple aspects of social-emotional health while using a nationally representative sample of participants ranging in age from early to middle adulthood.

To address these limitations, the current research will analyze the relationship between hearing loss and attributes of poor social-emotional health in participants ages 21-50 in a large, nationally representative sample. The goal of this research is to investigate the relationship between hearing loss and social-emotional health in early and middle adulthood by testing the following hypothesis: people with hearing loss will be more likely to struggle with poorer social-emotional health than people with typical hearing. 


\section{CHAPTER II}

\section{REVIEW OF LITERATURE}

Most of the literature published thus far on hearing loss and social-emotional health focuses primarily on participants in older adulthood, defined as 60 years and above (Dawes et al., 2015; Heffernan, Habib \& Ferguson, 2019). Additionally, many of the studies use small samples, ranging between 10 to 300 participants, with a few exceptions that include a variety of age groups, ranging between 6-year-old children and adults in their 70s. Prior studies show that literature regarding hearing loss and social-emotional health for this age group examines stigma, poor self-esteem, social isolation, and financial stress (Arslan, Aydemir, Kaya, Arslan \& Durmaz, 2018; Michael, Attias \& Raveh, 2019; Michael \& Zaidan, 2018; Xiang, An, Kang, Stagg, \& Ehrlich, 2020). Anxiety, depression, exhaustion, social isolation, and social-emotional health related to physical changes are the most relevant afflictions found in older adults with hearing loss (Arslan et al., 2018).

Social role theory and the life course perspective introduced by Newman \& Newman (2016) help explain the negative effects of hearing loss among older adults but also help to explain the stigma young and middle-aged adults face. These theoretical perspectives hypothesize young adults' negative attitudes and behaviors when they are diagnosed with hearing loss. Additionally, society's expectations that mostly older adults struggle with hearing loss and may exacerbate the stigma young and middle-aged adults face. Hearing loss is associated with financial strain, 
compromised social-emotional health, and amplifies the need to be close to audiologists (Kochkin, 1993; Jacobs, Noble, Bush, \& Snell-Rood, 2019). The life course perspective may lead to young and middle-aged adults feeling ashamed because they have to make steep healthcare and financial decisions that are typically reserved for older adults.

\section{Anxiety.}

Generalized Anxiety Disorder (GAD), as defined by the National Institute of Mental Health (2018) may present itself as restlessness, tiring easily, being irritable, constant feelings of worry, and sleeping difficulties. Typically, GAD significantly impacts a person for at least 6 months in many areas of their day to day life (work, school, and social interactions. A literature review conducted on the relationship between hearing loss and social-emotional health in studies of people over 18 years old and studies with samples larger than 30 found 25 studies including more than 17,130 people found that those with hearing loss were more likely to have or show symptoms of anxiety compared to people without hearing loss (Shoham, Lewis, Favarato, \& Cooper, 2019). Interestingly, this literature review found anxiety levels significantly decreased if participants had corrective surgery to fix their hearing loss (Shoham et al., 2019). Although this was an expansive study, it would have been stronger if they conducted research on participants themselves rather than examining findings from 25 individual studies.

A longitudinal study conducted by Abbas et al. (2019) of 100 people between the ages of 18 and $60(\mathrm{M}=45.38)$ found participants with hearing loss are more likely to be at risk for serious mental health disorders, especially anxiety. Idstad et al. (2019) 
examined 32,456 participants' childhood hearing loss and compared it to their mental health in adulthood and found a significant relationship between slight hearing loss and anxiety in women and poor self-esteem in women 20-39 years old with mild hearing loss. However, Idstad et al. (2019) did not find any significant differences when comparing childhood hearing loss and adult mental health in men.

Some studies show that those who are deaf or hard of hearing struggle with anxiety that can impact other parts of their life beyond day-to-day functions (Ariapooran, 2017). In addition to co-occurring mental health concerns, people with hearing loss are also more likely to struggle with anxiety-related physical issues such as disrupted sleep patterns (Clarke, Hoare, \& Killan, 2019). Clarke et al. (2019) found in their review of 16 peer-reviewed studies of adults 18 or older that disrupted sleep patterns may be a result of several kinds of hearing loss related-anxiety including auditory deprivation, communication anxiety, anxiety related to high-stress jobs, and social anxiety in conjunction with a person's age, existing hearing status, and depression. Similar to the study conducted by Shoham et al. (2019), this study was a scoping review of 16 peer-reviewed studies. These literature reviews provide substantial evidence that people with hearing loss also struggle with anxiety and anxiety-related physical issues.

A study conducted by Ariapooran (2017) in two Iranian cities of 63 middle school and high school students found statistically significant differences in mathrelated test anxiety, intrinsic and extrinsic motivation, self-efficacy, and performance among deaf, hard of hearing, and hearing students. Ariapooran's study (2017) found that deaf and hard of hearing students had higher intrinsic goal orientation and 
typically hearing students had lower levels of math-related anxiety and better mathematics performance. A hearing loss diagnosis, especially as a young or middleaged adult (21-50 years old), can be traumatic no matter the severity of the loss. Evidence shows a significant association between even slight levels of hearing loss and increased symptoms of anxiety in a relatively small study of 120 participants between 22-60 years old (Kobosko et al. 2018).

Prior studies found that hearing loss and social anxiety/social phobia are linked due to their intertwined nature. In a small study conducted by Eleuteri et al. (2010), 70 hearing aid or cochlear implant users, and 75 healthy adults between the ages of 18 and 65 , hearing loss was significantly related to lower levels of social functioning. Participants in the control group completed the following surveys: the Social Functioning Questionnaire, the Brief Symptom Inventory, the Liebowitz Social Phobia Scale, and the Body Uneasiness Test. In addition to the surveys listed, the experimental group also responded to the following surveys: the International Outcome Inventory for Hearing Aids, the Attitude towards Hearing Loss Questionnaire, and the Hearing Handicap Inventory for Adults. The findings of the study indicated hearing aid/cochlear implant users had significantly lower levels of social functioning $(p<0.05)$ and higher levels of anxiety, phobic anxiety, paranoid ideation, social phobia, body image preoccupation, and interpersonal insensitivity $(p<$ 0.05) (Eleuteri et al., 2010).

A small study conducted by Dehnabi, Radsephehr, and Foushtanghi (2017) examined if participating in a mindfulness-based stress reduction (MBSR) program would improve Social Anxiety Inventory (SAI) scores and help offset the anxiety- 
provoking nature of hearing loss. The 12 deaf individuals attended eight sessions, each covering a different topic including communication, muscle relaxation, general relaxation, breathing techniques, etc. and found through a sample of 24 individuals (12 deaf and 12 hearing) deaf participants' SAI scores were significantly lower compared to their pre-MBSR SAI scores and were more accepting of their fear-based physical symptoms (Dehnabi et al., 2017).

\section{Depression}

Many studies that discussed the prevalence of anxiety in people with hearing loss diagnoses also found an increased likelihood of depression (Abbas et al. 2019; Eleuteri et al., 2010; Knutson, Johnson, \& Murray, 2006; Kobosko et al., 2018). According to the National Institute of Mental Health (NIMH) in 2018, major depressive disorder (MDD) presents itself with a variety of symptoms such as feelings of hopelessness, irritability, difficulty concentrating, and fatigue. Many people who are diagnosed with hearing loss may struggle with physical, and mental, social, and emotional changes as well as denial about their condition, which are symptoms frequently seen in MDD (Akram, Batool \& Bibi, 2019; NIMH, 2018; Wallhagen, 2019).

Acquired hearing loss and perceived disability may lead to other aspects of psychological distress such as depression and anger. Ahmed, Aqeel, Akhtar, Salim, \& Ahmed (2020) studied hearing loss related stress, anxiety, depression, and tinnitus (ringing in the ears) and how anxiety and depression play a role in the relationship between hearing loss and tinnitus. Among 110 participants older than 18 years old with hearing loss and tinnitus, this study found a strong correlation between the 
severity of hearing loss and worsened psychological symptoms like depression and, therefore, a decreased quality of life (Ahmed et al. 2020). In a study conducted on 100 Pakistani participants (60 male and 40 female between 18 and 60 years old), hearing loss and tinnitus triggered psychological distress including depression, anxiety, stress, and mood swings (Abbas et al., 2019; Chepesiuk, 2005).

In older adults, two studies found that hearing status did not have a significant impact on depression but did have an impact on loneliness (Dawes et al., 2015; Pronk, Deeg, \& Kramer, 2013). The studies described above found that hearing aid use improved cognition but did not have a significant impact on depression (Dawes et al., 2015; Pronk et al., 2013). Another study conducted by Xiang et al. (2020) using data from the National Health Interview Surveys from 2010-2014 found that one-tenth of older adults are impaired in one or more major life activity (hearing, vision, cognition, mobility, etc.). Xiang et al. (2020) also found adults aged 50 or above with a disability are more likely to experience depression on a daily or weekly basis. Xiang et al (2020) explain that older adults who are more likely to have one or more impairment in a major life activity are also less likely to use mental health services.

\section{Exhaustion}

Fatigue is a common experience among people with hearing loss. A qualitative study conducted on 14 people aged 44-70 found they described exhaustion as requiring increased efforts, increased negative emotions, and sleep disruption (Holman, Drummond, Hughes, \& Naylor, 2019). Many people who live with hearing loss are required to assimilate into a hearing-oriented society and are more likely to be exhausted than their typically hearing counterparts (Holman et al., 2019). Holman et 
al. (2019) found that along with other factors such as lifestyle, coping strategies, sleep, etc., 14 adults $44-70$ years old experienced hearing loss-related fatigue. A fairly small study conducted among 16 college students comparing those with hearing loss (23-32 years old) and those without hearing loss (22-31 years old) found students with hearing loss required more effort and focus, and as a result, had heightened cortisol levels (Dwyer et al. 2019). Consistently high cortisol levels and acute stress can lead to emotional exhaustion and physical illnesses such as metabolic syndrome, mood disorders, diabetes, and cardiovascular disease (Dwyer et al. 2019; Hasson et al. 2013; Hlayisi, Petersen, \& Ramma, 2018). Here, we can see that fatigue, an often forgotten consequence of hearing loss, may also play a role in the likelihood of a person experiencing depression and anxiety.

\section{Social Isolation}

People who struggle with hearing loss often feel isolated which also contributes to poorer mental health (Dawes et al., 2015; Heffernan et al., 2019). Hearing loss and deafness are isolating in nature and a study of 2,300 adults with hearing loss aged 50 or older struggled to participate in social activities (Reinemer \& Hood, 1999). A study conducted on 178 people with hearing loss between the ages of 17 to $84(\mathrm{M}=50.9 ; \mathrm{SD}=15.3)$ found there were heightened levels of social introversion and loneliness (Knutson et al., 2006). Additionally, a 2-phased (P1 $\mathrm{M}_{\mathrm{age}}=63.0 ; \mathrm{SD}=12.1$ and $\left.\mathrm{P} 2 \mathrm{M}_{\mathrm{age}}=62.5 ; \mathrm{SD}=11.2\right)$ study examined the impact of hearing loss has on characteristics of social isolation (Heffernan et al., 2019). Social isolation is magnified and its effects are especially devastating for people who live in rural communities. In a study conducted on 71 participants with hearing loss $(\mathrm{M}=65.1$; 
$\mathrm{SD}=13.7)$ and 45 people without hearing loss $(\mathrm{M}=61.2 ; \mathrm{SD}=7.6)$, found those who lived in rural parts of Alabama indicated they did not have as much tangible social support as compared to those who lived in urban settings (Hay-McCutcheon, Hyams, Yang, \& Parton, 2018).

People diagnosed with sudden unilateral hearing loss also struggle with many physical changes such as vertigo and tinnitus which may contribute to social isolation and increased levels of depression in people aged 20-58 (M=32.8; $\mathrm{SD}=9.9)$ (Arslan et al, 2018). If adults are not provided with the information to encourage appropriate socialization, this may exacerbate the isolating nature of being deaf or hard of hearing (Hay-McCutcheon et al., 2018; Zaidman-Zait, Most, Tarrasch, Haddad-eid, \& Brand, 2016).

\section{Use of Hearing Aids}

There are many reasons why young and middle-aged adults with hearing loss who could benefit from hearing aids do not use them as explained by the social role theory and the life-course perspective (Newman \& Newman, 2016). Since hearing loss is stigmatizing for older adults, social role theory and the life course perspective predict young and middle-aged adults will face age-related stigma. The life course perspective and social role theory may also predict the stigma surrounding hearing aid use as well.

A study conducted by Kochkin (1993) found that adults between the ages of 35 and 44 were twice as likely to not use a hearing aid due to stigma compared to adults between the ages of 75 and 84 . Many people with hearing loss do not use hearing aids because they amplify all noise and do not fix hearing like glasses correct a person's 
eyesight to 20/20 (Clason, 2015; NIDCD, 2013). Many hearing aid users are bothered by the background noise amplified by hearing aids which can make social gatherings difficult (NIDCD, 2013).

Another reason a person may not use hearing aids is due to the financial cost. Michael et al. (2019) found that participants' ability to pay for hearing aids or cochlear implants affected their ability to participate in social activities. Higher levels of selfacceptance, advocacy, and financial well-being were related to better self-esteem if participants had the means to pay for hearing aids or cochlear implants (Michael et al., 2019). The stigma and poor self-esteem associated with a hearing loss diagnosis are exacerbated in part to the high cost of assistive technology and one's limited access to an audiologist (Michael et al. 2019; Powell et al., 2019).

Many people cannot purchase hearing aids and cochlear implants without financial assistance. Research indicates that the cost of a pair of hearing aids $(\$ 4,700$ in 2013) may deter people from purchasing them because they cannot afford them (Blazer \& Tucci, 2018). If a person is unable to purchase aids but could benefit from them, it can have a chain effect on his or her mental health, quality of life, and social interaction. Demographic barriers may impact people's ability to access audiologists and hearing aids which may also impact their social-emotional health. Powell et al. (2019) found participants between 50 and 78 years old faced financial and physical barriers to audiologists especially if they lived in rural areas. Overall, a person's demographic location (urban vs. rural), annual income, and level of social support may impact whether adults with hearing loss can receive treatment (Hay-McCutcheon et al., 2018). 


\section{Justification of the Current Study.}

Extant literature has primarily focused on the impact of hearing loss on physical, social, mental, and emotional health in older adults and used small, nonrepresentative samples (Amieva et al. 2018; Blazer \& Tucci, 2018; Castiglione et al., 2016). However, there is far less research surrounding social-emotional health in young to middle-aged adults between 21 and 50 years old with hearing loss. Using a nationally representative sample, this study asks the following research question about the relationship between hearing loss and social-emotional health: Do people with hearing loss have poorer social-emotional health as compared to people with typical hearing? Finally, this study will also examine an exploratory question: Do people with hearing loss who use a hearing aid have better social-emotional health as compared to people with hearing loss who do not use a hearing aid? 


\section{CHAPTER III}

\section{METHODOLOGY}

\section{Procedure}

This study used a secondary dataset from the 2011 wave of the National Health Interview Survey (NHIS). The overall purpose of this cross-sectional NHIS study is to acquire information about the frequency and distribution of illness across the United States. Available on the Inter-University Consortium for Political and Social Research (ICPSR) website through the University of Michigan, this study gathered data on the household level, family level, and the person level. To prepare the data for analysis, the three levels of data (household, family, and person) provided by the NHIS were combined with the sample adult and adult disability files. The data collected in this study are cross-sectional and reached all fifty states and the District of Columbia. Members of the research team acquired their information from clinical data and survey data via computer-assisted personal interviews (CAPIs), face to face interviews, and telephone interviews.

\section{Sample}

The 2011 wave of the NHIS accrued 16,540 respondents. The adults selected for the sample adult questionnaire were randomly selected within the family data level. Within the sample, 8,652 participants are between 21 and 50 years old. For the current study, participants between the ages of 21 and 50 years old with all data present who do not use a hearing aid $(n=8,261)$ are included in the analyses. 
Participants who use a hearing aid were excluded from the main analyses because most of the participants with hearing aids indicated they did not have difficulty with hearing, thus we could not identify their true hearing ability. Within the sample, over $75 \%$ of participants who use hearing aids indicated they do not have difficulty hearing. Finally, participants who have access to hearing aids are often demographically different than those who do not have access to hearing aids.

As shown in table 1, the sample in the 2011 wave of the NHIS is diverse. A majority of the sample was male (54\%). About $46 \%$ of the participants are married or cohabitating. Nearly $70 \%$ of the sample had an annual income of less than $\$ 45,000$ and about $30 \%$ of the sample earned $\$ 45,000$ or more in 2010 . The participants in this study come from four main regions: Northeast (15\%), Midwest (23\%), South $(35 \%)$, and West (27\%). Approximately three-quarters of the participants in this study were White, $16 \%$ were Black, $8 \%$ were Asian, and less than $2 \%$ were another race.

The demographic differences between the group who responded to all of the questions used in the analyses and those who had missing data are shown in Table 2. Age (in years) is significantly different $(\mathrm{p}=0.009)$ as only $33 \%$ of participants with all data present were likely to be 41 years old or older as compared to $42 \%$ of participants with missing data. The use of a hearing aid was also significantly different $(\mathrm{p}=0.019)$ because nearly $5 \%$ of participants with missing data and only $2 \%$ of participants with all data present used a hearing aid. Approximately $45 \%$ of participants were married or cohabitating in the group with all data present as compared to only $37 \%$ of participants with missing data which was statistically significant $(p=0.015)$. 
Table 1. Demographics of Participants 21-50 years old based on Data Present

\begin{tabular}{|c|c|c|c|c|}
\hline & $\begin{array}{l}\text { Has All Data } \\
(n=8,402) \\
\%(n)\end{array}$ & $\begin{array}{l}\text { Has Missing Data } \\
(n=250) \\
\%(\mathrm{n})\end{array}$ & Chi-Square & $\mathrm{p}$-value \\
\hline Age (in Years) & & & 9.842 & $0.009 * *$ \\
\hline $21-30$ & $33.0(2,773)$ & $30.8(77)$ & & \\
\hline $31-40$ & $34.3(2,885)$ a & $27.6(69)_{b}$ & & \\
\hline $41-50$ & $32.7(2,744)_{\mathrm{a}}$ & $41.6(104) \mathrm{b}$ & & \\
\hline Difficulty Hearing & & & 0.015 & 0.903 \\
\hline No Difficulty & $82.5(6,930)$ & $83.0(78)$ & & \\
\hline Some Difficulty & $17.5(1,470)$ & $17.0(16)$ & & \\
\hline Use Hearing Aid? & & & 5.509 & $0.019 *$ \\
\hline Yes & $1.7(141)$ & $4.6(5)$ & & \\
\hline No & $98.3(8,261)$ & $95.4(103)$ & & \\
\hline Income & & & 0.131 & 0.717 \\
\hline Less than $\$ 45,000$ & $69.5(4,119)$ & $71.0(93)$ & & \\
\hline More than $\$ 45,000$ & $30.5(1,806)$ & $29.0(38)$ & & \\
\hline Sex & & & 0.037 & 0.848 \\
\hline Male & $45.8(3,847)$ & $46.4(116)$ & & \\
\hline Female & $54.2(4,555)$ & $53.6(134)$ & & \\
\hline Marital Status & & & 5.913 & $0.015 *$ \\
\hline Married/Cohabitation & $44.9(3,769)$ & $36.8(44.6)$ & & \\
\hline Other & $55.1(4,633)$ & $55.4(4,779)$ & & \\
\hline Race & & & 5.707 & 0.127 \\
\hline White & $74.6(6,269)$ & $70.4(176)$ & & \\
\hline Black & $15.7(1,323)$ a & $20.8(52) \mathrm{b}$ & & \\
\hline Asian & $7.9(665)$ & $8.0(20)$ & & \\
\hline Other & $1.7(145)$ & $0.8(2)$ & & \\
\hline Region in the US & & & 1.612 & 0.675 \\
\hline Northeast & $15.2(1,274)$ & $16.4(41)$ & & \\
\hline Midwest & $22.5(1,887)$ & $23.2(58)$ & & \\
\hline South & $35.4(2,976)$ & $31.6(79)$ & & \\
\hline West & $27.0(2,265)$ & $28.8(72)$ & & \\
\hline
\end{tabular}

\section{Measures}

The measures described below, used in conjunction with the sample from the NHIS 2011 wave of the Adult Functioning and Disability Supplement (AFD), were developed by members of the Washington Group (WG) on Disability Statistics and the Budapest Initiative (BI) on the Measurement of Health State based on the World 
Health Organization, International Classification of Functioning, Disability, and Health (ICF). These measures have been used in several national surveys and censuses and have been tested globally (Washington Group on Disability Statistics, 2016).

\section{Independent Variables}

Hearing Loss

To measure hearing loss, participants answered 1-no difficulty, 2 -some difficulty, 3-a lot of difficulty, 4-cannot do at all/unable to do when responding to the following prompt: the degree of difficulty hearing conversation with one person in a quiet room. The variable to measure participants' difficulty hearing was recoded into a dichotomous variable where 1-Yes (which consists of original coding 2-4) and 2-No.

\section{Hearing Aid Use}

For the exploratory analyses, hearing aid use is measured based on participants' answer to the following question: Do you use a hearing aid? Hearing aid use was measured via a dichotomous variable where 1-Yes and 2-No.

\section{Dependent Variable}

\section{Social-Emotional Health}

The original NHIS study relied on single items to measure the constructs of anxiety, depression, exhaustion, and social isolation. For the current study, the four components were merged into a social-emotional health scale to provide a stronger scale rather than testing each construct individually. The original items used in the NHIS for anxiety, depression, exhaustion, and social isolation are described below. 


\section{Anxiety and Depression}

To measure anxiety, the study asked the following: How often do you feel worried, nervous, or anxious? To measure depression, the study asked, How often do you feel depressed? The response scales used to indicate a participant's frequency of anxiety and depression were the same: 1-daily, 2-weekly, 3-monthly, 4-a few times a year, and 5-never.

\section{Exhaustion}

To operationalize exhaustion, this study used participants' responses to the following question: "how often felt very tired or exhausted in the past 3 months?" Participants answered 1 if they never felt tired or exhausted, 2 if they felt tired or exhausted some days, 3 if they felt tired or exhausted most days, and 4 if they felt tired or exhausted every day.

\section{Social Isolation}

A person's social isolation was measured using participants' responses about whether they have difficulty participating in leisure or social activities. The responses to this scale were similar to those for exhaustion where 1-no difficulty, 2-some difficulty, 3-a lot of difficulty, and 4-cannot do at all/unable to do.

\section{Social-Emotional Health Scale}

To merge these 4 items into a new scale to measure social-emotional health, the following steps occurred. First, the anxiety and depression scales were recoded by combining 3 (monthly) and 4 (a few times a year) into one category named "sometimes", resulting in the following scale: 1-Always, 2-Often, 3-Sometimes, and 4-Never. The scales for anxiety and depression were then reverse coded where 1- 
never, 2-sometimes, 3-often, and 4-always. This coding is similar to the exhaustion and social isolation scales. The scales to measure exhaustion and social isolation have similar response categories: 1-never (never felt exhausted/no difficulty), 2-sometimes (felt exhausted some days/some difficulty), 3-often (felt exhausted most days/a lot of difficulty), and 4-always (felt exhausted every day/cannot do or unable to do).

To create a new scale to measure social-emotional health, these four items were summed into one scale. The sum of the scale ranges from 4 to 16 . Lower scores indicate better social-emotional health and higher scores represent poorer socialemotional health. To test the strength of the new social-emotional health measure, a Cronbach's Alpha reliability scale was conducted. The results of the reliability for participants' between 21 and 50 years old was $\alpha=0.69$ which indicates the scale is a reliable measure of social-emotional health.

\section{Demographic Covariates}

The demographic variables reported in the NHIS survey were extensive and for this study, were combined into smaller mutually exclusive groups. Age was reported as an integer between $18-85+$ years and was transformed into three similarly divided groups $(21-30,31-40$, and 41-50) in order to identify differences among emerging adults, young adults and middle-aged adults. Participants ages 18-20 and participants older than 50 were excluded because the purpose of the study is to focus on the impacts of hearing loss on young and middle-aged adults. According to the 2011 Census, the threshold for median income in the United States was \$50,054. Annual income was reported with eleven categories and was recoded into two categories (less than $\$ 45,000$ and more than $\$ 45,000$ ) which most closely matches the median income 
threshold in 2011. Finally, marital status was originally reported in seven groups and was recoded into two groups, married or cohabitating and other. Region (Northeast, Midwest, South, and West), sex (male and female), and race (White, Black, Asian, and Other) maintained their original coding.

\section{Data Analysis}

To analyze the 2011 wave of the NHIS, SPSS software version 26.0 was used. Frequencies and descriptives on key variables (hearing ability, age, income, region, marital status, and race) were run to have a better understanding of the variables being used in the study and to identify participants with missing data. Crosstabs were conducted to identify significant demographic differences between participants with all of their data present and those with missing data in order to generalize the findings. Crosstabs were also conducted to compare demographics based on participants' hearing ability. Significant demographic differences were identified to provide a possible alternative explanation for social-emotional health scores regardless of participants' hearing ability.

To examine the relationship between hearing loss and social-emotional health, this study tested the hypothesis (a person with hearing loss will be more likely to experience poorer social-emotional health than a person with typical hearing) by conducting an independent samples $t$-test, using difficulty hearing as the independent variable and the newly created social-emotional health scale as the dependent variable. The results for the hypotheses will be considered significant if $p<0.05$. To examine the relationship between demographic variables income, race, gender, and marital 
status with social-emotional health, another independent samples $t$-test was conducted. The results for the hypotheses will be considered significant if $p<0.05$.

A linear regression was conducted to identify if significant differences among the demographic data influenced the results from the independent samples $t$-test. Dummy variables (i.e. 1-Northeast, 0-Else, 1-Midwest, 0-Else, etc.) were created for age, region, gender, marital status, and race. The lowest coded group within each demographic variable with two or more groupings were excluded. The linear regression consists of a two-step model with demographic variables entered on the first step, and hearing difficulty in the second step. A significant effect is signaled by a significant change in the $\mathrm{R}$ square (explained variance) when hearing difficulty is added to the model. The results of the linear regression will be considered significant if $p<0.05$.

An exploratory analysis was conducted to identify if hearing aid use impacts social-emotional health scores among participants with hearing loss. An independent samples t-test was conducted on participants with hearing loss where hearing aid use was the independent variable and the social-emotional health scale was the dependent variable. The results of the independent samples t-test were considered significant if $p$ $<0.05$. 


\section{CHAPTER IV}

\section{FINDINGS}

The first set of demographic analyses using crosstabs to compare participants with typical hearing and participants with hearing loss revealed significant differences in all but one of the demographic variables, income (see table 2). Older participants (41-50) are significantly more likely to fall in the "some difficulty" hearing group and younger participants are significantly more likely to fall in the "no difficulty" hearing group. Males are significantly more likely to fall in the "some difficulty" hearing group and females are more likely to fall in the "no difficulty" hearing group. Participants who are married or cohabitating are more likely to fall in the "no difficulty" hearing group and participants who were not married or cohabitating were more likely to fall in the "some difficulty" hearing group. White participants are significantly more likely to fall into the "some difficulty" hearing group. Finally, participants from the Northeast region of the United States were more likely to fall into the "no difficulty" hearing group. 
Table 2. Demographic Differences of Participants 21-50 based on Hearing Ability

\begin{tabular}{|c|c|c|c|c|}
\hline & $\begin{array}{l}\text { No Difficulty } \\
(n=6,813) \\
\%(n)\end{array}$ & $\begin{array}{l}\text { Some Difficulty } \\
(n=1,446) \\
\%(n)\end{array}$ & Chi-Square & p-value \\
\hline Age (in Years) & & & 55.383 & $0.000 * * *$ \\
\hline $21-30$ & $34.4(2,337)$ a & $27.5(2,734)_{b}$ & & \\
\hline $31-40$ & $34.8(2,371) \mathrm{a}$ & $31.8(460) \mathrm{b}$ & & \\
\hline $41-50$ & $30.9(2,105)$ a & $40.7(589) \mathrm{b}$ & & \\
\hline Income & & & 2.986 & 0.084 \\
\hline Less than $\$ 45,000$ & $70.0(3,409)$ & $67.3(710)$ & & \\
\hline More than $\$ 45,000$ & $30.0(1,461)$ & $32.7(345)$ & & \\
\hline Sex & & & 6.988 & $0.008 * *$ \\
\hline Male & $45.1(3,076)$ & $49.0(708)$ & & \\
\hline Female & $54.9(3,737)$ & $51.0(738)$ & & \\
\hline Marital Status & & & 14.542 & $0.000 * * *$ \\
\hline Married/Cohabitation & $45.8(3,121)$ & $40.3(583)$ & & \\
\hline Other & $54.2(3,692)$ & $59.7(863)$ & & \\
\hline Race & & & 31.759 & $0.000 * * *$ \\
\hline White & $73.6(5,014)_{\mathrm{a}}$ & $79.9(1,156)_{b}$ & & \\
\hline Black & $16.1(1,095)$ a & $13.3(193) \mathrm{b}$ & & \\
\hline Asian & $8.6(586)$ а & $5.0(72) \mathrm{b}$ & & \\
\hline Other & $1.7(118)$ & $1.7(25)$ & & \\
\hline Region in the US & & & 16.542 & $0.001 * *$ \\
\hline Northeast & $15.7(1,072)_{\mathrm{a}}$ & $12.0(173)_{b}$ & & \\
\hline Midwest & $22.2(1,513)$ & $24.4(353)$ & & \\
\hline South & $35.5(2,416)$ & $34.6(501)$ & & \\
\hline West & $26.6(1,812)$ & $29.0(419)$ & & \\
\hline
\end{tabular}

An independent-samples t-test was conducted to compare social-emotional health in participants with difficulty hearing to participants who do not have difficulty hearing (see table 3). The results show participants with hearing loss are more likely to have higher social-emotional health scores, $\mathrm{M}=7.58(\mathrm{SD}=2.43)$ indicating poorer social-emotional health, as compared to participants with typical hearing, $M=6.20$ $(\mathrm{SD}=2.01)$. These results indicate that hearing loss is significantly correlated to a person's social-emotional health, $p<0.001$. 
Table 3. Independent Samples T-Test based on Hearing Ability

\begin{tabular}{lclll}
\hline Variable & $\mathrm{n}$ & Mean (SD) & t-statistic & p-value \\
\hline & & & -20.041 & $0.000^{*}$ \\
No Difficulty Hearing & 6,809 & $6.20(2.01)$ & & \\
Some Difficulty Hearing & 1,445 & $7.58(2.43)$ & & \\
\hline
\end{tabular}

$* p<0.001$

A linear regression was conducted to adjust for any influence demographic variables have on social-emotional health scores (see table 4). The results of the linear regression found after controlling for significant demographic differences between participants with difficulty hearing and those with typical hearing, hearing ability significantly predicts social-emotional health scores: $\mathrm{F}(11,8,242)=78.899, p<0.001$. The linear regression results show that $9.4 \%$ of the variance in the data can be explained by participants' hearing abilities $\left(\mathrm{R}^{2}=0.041\right)$ and that there is a moderate relationship between the demographic variables and hearing ability $(\mathrm{R}=0.309)$. Finally, difficulty hearing has a substantial impact on social-emotional health scores because variance more than doubled $\left(\mathrm{R}^{2}=0.094\right)$ after adding this variable to the regression equation. 
Table 4. Linear Regression of Difficulty Hearing Controlling for Demographic Variables

\begin{tabular}{|c|c|c|c|c|c|c|}
\hline & \multicolumn{3}{|c|}{ Model 1} & \multicolumn{3}{|c|}{ Model 2} \\
\hline Variable & B & SE & $\beta$ & B & SE & $\beta$ \\
\hline Female (vs. Male) & 0.546 & 0.047 & $0.126^{* * *}$ & 0.568 & 0.045 & $0.131 * * *$ \\
\hline $\begin{array}{l}\text { Not Married (vs. Married) } \\
\text { Age (vs. 21-30) }\end{array}$ & 0.598 & 0.049 & $0.138 * * *$ & 0.535 & 0.047 & $0.124 * * *$ \\
\hline $\begin{array}{l}31-40 \\
41-50\end{array}$ & $\begin{array}{l}0.244 \\
0.361\end{array}$ & $\begin{array}{l}0.058 \\
0.059\end{array}$ & $\begin{array}{l}0.054 * * * \\
0.079 * * *\end{array}$ & $\begin{array}{l}0.207 \\
0.252\end{array}$ & $\begin{array}{l}0.056 \\
0.057\end{array}$ & $\begin{array}{l}0.046 * * * \\
0.055 * * *\end{array}$ \\
\hline $\begin{array}{l}\text { Race (vs. White) } \\
\text { Black } \\
\text { Asian }\end{array}$ & $\begin{array}{l}-0.260 \\
-0.575\end{array}$ & $\begin{array}{l}0.067 \\
0.087\end{array}$ & $\begin{array}{l}-0.044 * * * \\
-0.072 * * *\end{array}$ & $\begin{array}{l}-0.202 \\
-0.482\end{array}$ & $\begin{array}{l}0.065 \\
0.085\end{array}$ & $\begin{array}{l}-0.034 * * \\
-0.061 * * *\end{array}$ \\
\hline $\begin{array}{c}\text { Other } \\
\text { Region (vs. Northeast) }\end{array}$ & 0.066 & 0.179 & 0.004 & 0.094 & 0.174 & 0.006 \\
\hline $\begin{array}{l}\text { Midwest } \\
\text { South }\end{array}$ & $\begin{array}{l}0.261 \\
0.277 \\
0211\end{array}$ & $\begin{array}{l}0.077 \\
0.072 \\
0.075\end{array}$ & $\begin{array}{l}0.051 * * \\
0.061 * * * \\
0.043 * *\end{array}$ & $\begin{array}{l}0.197 \\
0.229 \\
0141\end{array}$ & $\begin{array}{l}0.075 \\
0.070 \\
0.073\end{array}$ & $\begin{array}{l}0.038 * * \\
0.051 * * \\
0.029\end{array}$ \\
\hline $\begin{array}{l}\text { Difficulty Hearing (vs. No } \\
\text { Difficulty) }\end{array}$ & 0.211 & & $0.04 J$ & -1.317 & 0.060 & $0.232 * * *$ \\
\hline F Change & & & $36.259 * * *$ & & & $484.053 * * *$ \\
\hline $\begin{array}{l}\text { DF } \\
\text { Adjusted } r^{2}\end{array}$ & & & $\begin{array}{l}10,8243 \\
0.041\end{array}$ & & & $\begin{array}{l}1,8242 \\
0.094\end{array}$ \\
\hline
\end{tabular}

$* p<0.05, * * p<0.01, * * * p<0.001$

The findings of the exploratory analysis comparing social-emotional health scores of those with hearing loss who use hearing aids to participants with hearing loss who do not use hearing aids were not significant. However, participants with hearing loss who used hearing aids had slightly lower mean scores $(M=7.08 ; S D=2.89)$, indicating better social-emotional health as compared to those with hearing loss who do not use hearing aids had slightly higher mean scores $(\mathrm{M}=7.58 ; \mathrm{SD}=2.43)$. 


\section{CHAPTER V}

\section{DISCUSSION}

The findings of this study via an independent samples t-test support the hypothesis that social-emotional health scores of participants 21-50 years old with typical hearing and participants who have difficulty hearing are significantly different. In the current study of adults 21-50 years old, we can see increased levels of depression, anxiety, exhaustion, and social isolation in participants with some degree of difficulty hearing compared to participants with typical hearing. The findings of this study align with prior research conducted on children and older adults.

Most of the findings of this study are similar to those in prior studies examining the relationship between hearing loss and mental health. Although the analyses were conducted using a sum of individual items to measure the socialemotional health, the individual items used to create the scale included several constructs used in prior studies. Previous studies found hearing loss contributes to increased levels of psychological distress and exhaustion (Abbas et al., 2019; Chepesiuk, 2005; Dwyer et al. 2019; Kobosko et al. 2018). Ahmed et al. (2020) stated in their article that hearing loss is also related to a decreased quality of life. One study conducted by Idstad et al. (2019) did not find a significant relationship between men's childhood hearing loss and their adult mental health status. Overall, most of the prior studies aligned with the findings of the current study. 
The life course perspective and social role theory may influence participant self-report scores because they help explain society's understanding of what is considered "normal" development. Since these expectations are set based on a person's age, gender, and ability, young and middle-aged adults may feel ashamed to admit their severity of hearing loss and/or mental health symptoms. If hearing loss and hearing aid use are especially stigmatizing for older adults, young and middle-aged adults may be even more reluctant to admit they have difficulty hearing because they are "too young" and do not fit in 'traditional' life patterns. Therefore, social role theory and the life course perspective may explain people's denial which prohibits them from acknowledging the severity of the problem, seeing an audiologist, and purchasing or using hearing aids (Crocker \& Major, 1989; Xiang et al. 2020). According to the life course perspective and social role theory, young and middle-aged adults may feel they are too young to be dealing with hearing loss because they feel that they are dealing with issues that only afflict older adults.

This study found several significant demographic differences between participants with and without difficulty hearing. Participants $21-40$, females, Blacks, Asians, and those living in the Northeast were significantly more likely to have typical hearing. Some of these demographic differences were expected (age and gender) because men are twice as more likely to struggle with hearing loss as compared to women (Plotnick, 2017). Additionally, the National Institute on Deafness and Other Communication Disorders (NIDCD) (2018) states that one-third of adults in the United States between 65 and 74 have hearing loss and nearly half of adults over 75 have hearing loss which is to be expected. Other demographic differences were not 
expected (race and region). Racial minorities were more likely to have typical hearing as compared to their Caucasian counterparts, which was unexpected because according to the Bureau of Labor Statistics (2011), a larger percentage of racial minorities work in service occupations where they are exposed to louder environments. However, according to Healthy People 2020, the high rate of testing among Blacks and African Americans may have offset their predisposition to hearing loss (NHANES). Finally, it was surprising that participants in the Northeast region of the United States were more likely to have typical hearing because prior studies found those who live in cosmopolitan areas were more likely to have difficulty hearing compared to those living in small towns and rural areas (Kumar et al. 2017; Wang et al. 2019).

When comparing social-emotional health scores, regardless of hearing ability, Caucasian participants, males, and participants who were Married/Cohabitating were significantly more likely to have lower mean scores, indicating better social-emotional health. Most of the statistically significant differences among participants' demographics in relation to social-emotional health scores were not surprising. Having moral support via a partner or spouse may relieve some stress surrounding hearing loss and financial burdens. The association between social-emotional health scores among demographic attributes reminds us that hearing loss is only one factor that contributes to a person's social-emotional health. The findings of the exploratory analysis comparing participants with difficulty hearing who use a hearing aid to those with hearing loss who do not use a hearing aid were not statistically significant. However, participants with hearing loss who use hearing aids had a slightly lower mean 
indicating better social-emotional health compared to those with hearing loss who do not use a hearing aid.

\section{Limitations}

The studies referenced in the literature review identified participants' hearing loss in several ways. Some studies used self-reporting measures, similar to the current study (Abbas et al., 2019; Amieva et al., 2018) and others categorized hearing loss by decibel thresholds (mild - 26 to $40 \mathrm{~dB}$, moderate - 41 to $55 \mathrm{~dB}$, etc.) (Arslan et al, 2018). However, other studies did not specify how they measured hearing loss and only used terms and phrases such as "Deaf or Hard of Hearing" and "significant hearing loss as adults" (Ariapooran, 2017; Blazer \& Tucci, 2019).

One limitation of this study is that the data in the NHIS studies are selfreported. Self-report of perceived hearing ability may not be as reliable as measuring a person's hearing loss through conducting an audiogram and analyzing hearing loss via concrete results measured in decibels (dB) (Chepesiuk, 2005). Self-report data is a limitation of this study because the data are likely to be correlated due to the identical nature of the self-report measures for social-emotional health and perceived hearing ability and therefore do not show "cause."

Another limitation of this study is that the scale used to measure socialemotional health was created by adding participants' responses from four individual items. Although the reliability of the newly created social-emotional health measure was strong ( $\alpha=0.69)$, more robust and widely used questionnaires to measure anxiety, depression, and social-emotional health would have resulted in more reliable findings. Since secondary data were used in this study, the availability of specific information 
about the data was limited. The exploratory analyses examined participants with hearing loss and the impact hearing aid use has on their social-emotional health. Those who had hearing difficulties who used hearing aids had slightly improved socialemotional health. However, most of the participants with hearing loss indicated they did not use hearing aids, and many who indicated they did use hearing aids stated they did not have difficulty hearing. Fewer participants, perhaps due to stigma, responded to questions regarding hearing loss and hearing aid use which may have impacted the study's results and overall response rate.

\section{Future Directions}

These results indicate that hearing loss negatively impacts young and middleaged adults' self-reported social-emotional health scores. Additionally, after significant demographic covariates were controlled for, hearing loss still had a significantly negative impact on social-emotional health scores. These results have implications for several professionals especially audiologists, otolaryngologists, and mental health clinicians. In order to have a holistic approach for treating people who have hearing loss, it is important to address their social-emotional health as well as their auditory condition. Thus far, research has found a significant relationship between hearing loss and social-emotional health. Aside from treating veterans' mental health with hearing loss, there have been few mental health resources focused specifically on anxiety, depression, exhaustion, and social isolation related to hearing loss diagnoses (Carlson et al, 2019; Clifford, Baker, Risbrough, Huang, \& Yurgil, 2018; Maynard, Trivedi, Nelson, \& Fihn, 2018). Since hearing loss presents a unique set of challenges, especially for young and middle-aged adults, integrated care may be 
the future of healthcare. Knowing that hearing loss impacts a person's socialemotional health, it is critical to educate physicians, audiologists, otolaryngologists that treating the biological aspect of hearing loss is not enough. On the other hand, mental health clinicians, educators should also understand that hearing loss can impact people's social-emotional health. Therefore, integrated care may lead to better societal and professional understandings regarding the complex nature of hearing loss.

In 2017, the 115th United States' Congress passed legislation that requires hearing aids to be available over-the-counter this year (The Food and Drug Reauthorization Act of 2017). The legislation also specifies that over-the-counter hearing aids (OTC HAs) must be sold with a disclaimer label and that state or local governments cannot interfere with the Food and Drug Administration (FDA) Reauthorization Act of 2017. Prior to the passing of this legislation, hearing aids were regulated by the FDA as class I or II medical devices meaning they could only be distributed by medical professionals. According to the FDA Reauthorization Act of 2017, adults 18 or above with mild to moderate hearing loss would have the opportunity to self-assess and self-regulate their OTC HAs.

If the same analyses were conducted for NHIS data in 2021 after the country has a chance to feel the effects of this legislation, the results may differ due to easier access to hearing aids. Orji et al (2020) found globally $83 \%$ of people who could benefit from a hearing aid do not use one and only 67.9 of 401.4 million use them. Preventative measures like OTC HAs may reduce the risk of hearing loss-related depression, further hearing loss, and tinnitus if it is identified and treated earlier in rural areas in the United States (Jafari, Kolb, \& Mohajerani, 2019; Powell et al., 
2019). In a study conducted with participants in rural areas in Kentucky, many participants expressed concern about access to audiologists and hearing aid costs (Powell et al. 2019). Moreover, OTC HAs may be a beneficial option for people in rural areas where audiologists are sparse or in lower socioeconomic neighborhoods where the cost of hearing aids may discourage people from buying them. While hearing aids are shrinking and technology is evolving, OTC HAs may be a gamechanger for Americans who do not have access to audiologists or the financial means to buy them. However, audiologist, Sarah Sydlowski (2018), believes that while some could benefit from this legislation, OTC HAs are not the best choice for everyone. In her article, "OTC HAs are coming-But they're not for everyone," she reminds readers that although the legislation will be helpful for most, treating hearing loss should still involve an audiologist. Similarly, removing audiologists from the "treating hearing loss equation," prohibits them from assessing their social-emotional health and making proper referrals.

Future research should focus on the relationship between hearing loss and social-emotional health using decibel $(\mathrm{dB})$ results from hearing tests rather than selfreport surveys. If researchers had access to a more accurate and definitive hearing diagnosis via audiological testing, it would be easier to examine social-emotional health scores in relation to specific $\mathrm{dB}$ loss. Additionally, the results of studying hearing aid use among those with hearing loss after OTC HAs are available this year may look a lot different compared to the results from the 2011 wave of the NHIS study. Finally, conducting a longitudinal study examining hard of hearing participants' social-emotional health before using hearing aids and 3, 6, and 12 months after using 
them would potentially provide a clearer relationship between hearing aid use and improved social-emotional health over a longer period of time. 


\section{BIBLIOGRAPHY}

Abbas, J., Aqeel, M., Jaffar, A., Nurunnabi, M., \& Bano, S. (2019) Tinnitus perception mediates The relationship between physiological and psychological problems among patients. Journal of Experimental Psychopathology, 10(3) 1-15.

Ahmed, A., Aqeel, M., Akhtar, T., Salim, S., \& Ahmed, B. (2020) Moderating role of stress, anxiety, and depression in the relationship between tinnitus \& hearing loss among patients. Pakistan Journal of Psychological Research, 34(4). 753-772.

Akram, B., Batool, M., Bibi, A (2019) Biological, psychological and environmental factors of Suicidal ideation among the patients with presbycusis. Isra Med J; 11(1): 55-59.

Amieva, H., Ouvrard, C., Meillon, C., Rullier, L. \& Dartigues, J. (2018) Death, depression, Disability, and dementia associated with self-reported hearing problems: A 25-year study. The Journals of Gerontology. Series A, Biological Sciences and Medical Sciences, 73(10) 1383-1389.

Ariapooran, S. (2017) Mathematics Motivation, Anxiety, and Performance in Female Deaf, Hard of Hearing, and Hearing Students. Communication Disorders Quarterly 38(3). 172-178

Arslan, F., Aydemir, E., Kaya, Y., Arslan, H. \& Durmaz, A. (2018) Anxiety \& Depression in patients with sudden one-sided hearing loss. ENT Journal, 97. 10-11.

Baldridge, D. \& Kulkarni, M. (2017) The shaping of sustainable careers post hearing loss: Toward greater understanding of adult onset disability, disability identity and career transitions. Human Relations, 70(10) 1217-1236. 
Blazer, D. \& Tucci, D. (2019) Hearing loss and psychiatric disorders: a review. Psychological Medicine 49, 891-897.

Bureau of Labor Statistics (2011) US Dept. of Labor, The Economics Daily, Occupational employment by race and ethnicity: bls.gov/opub/ted/2012/ted_20121026.htm

Campbell, L. (2019) Why Many Men Have a Harder Time Seeking Treatment for Mental Illness. Healthline.

Carlson, K., Gilbert, T., O’Neil, M., Zaugg, T., Manning, C., Kaelin, C., Thielman, E., Reavis, K. \& Henry, J. (2019) Health Care Utilization and Mental Health Diagnoses Among Veterans With Tinnitus. American Journal of Audiology, 28(1S), 181-190.

Castiglione, A., Benatti, A., Velardita, C., Favaro, D., Padoan, E., Severi, D...Martini, A. (2016) Aging, cognitive decline and hearing loss: Effects of auditory rehabilitation and training With hearing aids and cochlear implants on cognitive function and depression among Older adults. Audiology and Neurotology, 21(1). 21-28.

Chepesiuk, R. (2005) Decibel Hell. Environmental Health Perspectives 113(1) A34-A41

Clarke, N., Hoare, D. \& Killan, E. (2019) Evidence for an association between hearing impairment and disrupted sleep: Scoping review. American Journal of Audiology 28, 1015-1024.

Clason, D. (2015) How hearing loss is different than losing your vision. Healthy Hearing.

Clifford, R., Baker, D., Risbrough, V., Huang, M. \& Yurgil, K. (2019) Impact of TBI, PTSD, and Hearing Loss on Tinnitus Progression in a US Marine Cohort. Military Medicine, 184(11/12), 839-846. 
Crocker, J. \& Major, B. (1989) Social-Stigma and Self-Esteem: The Self-Protective Properties of Stigma. Psychological Review 96(4). 608-630.

David, D., Zoizner, G., \& Werner, P. (2018) Self-Stigma and Age-Related Hearing Loss: A Qualitative study of stigma formation and dimensions. American Journal of Audiology 27. 126-136.

Dawes, P., Emsley, R., Cruickshanks, K., Moore, D. Fortnum, H., Edmondson-Jones, M., McCormack, A., \& Munro, K. (2015) Hearing loss and cognition: The role of hearing aids, social isolation and depression. PloS One, 10(3) 1-9.

Dehnabi, A., Radsepehr, H., \& Foushtanghi, K. (2017) The effect of mindfulnessbased stress reduction on social anxiety of the deaf. Annals of Tropical Medicine and Public Health 10(5). 1248-1253.

DeNavas-Walt, C., Proctor, B., \& Smith, J. (2011) US Census Bureau, Current Population Reports. Income, Poverty, and Health Insurance Coverage in the US. US Government Printing Office, Washington, DC, 2012. 1-80.

Dwyer, R., Gifford, R., Bess, F., Dorman, M., Spahr, A., \& Hornsby, B. (2019) Diurnal cortisol levels and subjective ratings of effort and fatigue in adult CI users: A pilot study. American Journal of Audiology, 28(3). 686-696.

Eleuteri, F., Forghieri, M., Ferrari., S., Marrara, A., Monzani., D. \& Rigatelli, M. (2010) Psychopathological Distress, Body Image Perception \& Social Phobia in Patients with Hearing Aids \& Cochlear Implants. European Psychiatry $25(1) .482$

Goman, A \& Lin, F. (2016) Prevalence of Hearing Loss by Severity in the US. AJPH 106 (10). 1820-1822. 
Hasson, D., Theorell, T, Bergquist, J. \& Canlon, B (2013) Acute stress induces hyperacusis in women with high levels of emotional exhaustion. PloS One, 8(1). e52945.

Hay-McCutcheon, M., Hyams, A., Yang, X., \& Parton, J. (2018) Hearing loss and social support In urban and rural communities. International Journal of Audiology. 57(8). 610-617.

Hearing \& Balance: Hearing Aids (2013) National Institute on Deafness and Other Communication Disorders (NIDCD) United States Department of Health \& Human Services. 1-5.

Heffernan, E., Habib, A., \& Ferguson, M. (2019) Evaluation of the psychometric properties of The social isolation measure in adults with hearing loss. International Journal of Audiology, 58(1) 45-52.

Hlayisi, V., Petersen, L., \& Ramma, L. (2019) High prevalence of disabling hearing loss in young to middle-aged adults with diabetes. International Journal of Diabetes in Developing Countries, 39(1). 148-153.

Holman, J. Drummond, A., Hughes, S. \& Naylor, G. (2019) Hearing impairment and daily-life fatigue: a qualitative study. International Journal of Audiology 58(7). 408-416.

Hunter, A. (2018) There are more important things to worry about: Attitudes and behaviours towards leisure noise and use of hearing protection in young adults International Journal of Audiology, 57(6) 449-456. 
Idstad, M., Tambs, K., Aarhus, L., \& Engdahl, B. (2019) Childhood sensorineural hearing loss and adult mental health up to 43 years later: Results from the HUNT study. BMC Public Health, 19(1) 1-9.

Jafari, Z, Kolb, B. \& Mohajerani, M (2019) Age-related hearing loss and tinnitus, dementia risk, and auditory amplification outcomes. Ageing Research Reviews, 56, 100963.

Knutson, J., Johnson, A., \& Murray, K. (2006) Social and emotional characteristics of adults seeking a cochlear implant and their spouses. British Journal of Health Psychology 11.279-292.

Kobosko, J., Jedrzejczak, W., Gos, E., Geremek-Samsonowicz, A., Ludwikowski, M., \& Skarzynski, H. (2018). Self-esteem in the deaf who have become CI users as adults. PloS ONE 13(9): 1-18.

Kujawa, S. \& Liberman, M. (2006) Acceleration of Age-Related Hearing Loss by Early Noise Exposure: Evidence of a Misspent Youth. The Journal of Neuroscience 26(7). 2115-2123.

Kumar, Y., Sahu, J., Basod, A., Patel, N. (2017) The Comparative Study of Subtle Deafness in Cosmopolitan, Town and Rural Population. IAIM 4(1): 72-77.

Maynard, C., Trivedi, R., Nelson, K., \& Fihn, S. (2018) Disability Rating, Age at Death and Cause of Death in US Veterans with Service-Connected Conditions. Military Medicine, 183(11/12). e371-e376.

Michael, R., Attias, J., \& Raveh, E. (2019) Perceived quality of life among adults with hearing Loss: Relationships with amplification device and financial well-being. Rehabilitation Counseling Bulletin, 62(4) 234-242. 
Michael, R. \& Zidan, H. (2018) Differences in self-advocacy among HoH and typical hearing students. Research in Developmental Disabilities, 72, 118-127.

National Health and Nutrition Examination Survey. Centers for Disease Control and Prevention, National Center for Health Statistics. Healthy People 2020.

National Institute of Mental Health (2018). Anxiety. Retrieved March 21, 2015, from http://www.nimh.nih.gov/health/topics/eating-disorders/index.shtml

National Institute of Mental Health (2018). Depression. Retrieved Feb. 20, 2020, from https://www.nimh.nih.gov/health/topics/depression/index.shtml.

National Institute on Deafness and Other Communication Disorders (NIDCD) (2018) NIH Pub. No. 97-4235. US Department of Health \& Human Services. https://www.nidcd.nih.gov/health/age-related-hearing-loss \#1

Newman, B. \& Newman, P. (2016) Theories of Human Development. NY: Psychology Press, Taylor \& Francis Group.

Orji, A., Kamenov, K., Dirac, M., Davis, A., Chadha, S. \& Vos, T. (2020) Global and regional needs, unmet needs and access to hearing aids. International Journal of Audiology, 59(3), 166-172.

Palmer, A, Newsom, J, \& Rook, K. (2016) How does difficulty communicating affect the Social relationships of older adults? an exploration using data from a national survey. Journal of Communication Disorders, 62, 131-146.

Plotnick, B. (2017) Men's health: protecting hearing an important priority. Healthy Hearing.

Powell, W., Jacobs., J, Noble, W., Bush, M. \& Snell-Rood, C. (2019) Rural adult perspectives on impact of hearing loss \& barriers to care. Journal of Community 
Health, 44(4). 668-674.

Pronk, M., Deeg, D., \& Kramer, S. (2013) Hearing status in older persons: A significant determinant of depression and loneliness? Results from the longitudinal aging study Amsterdam. American Journal of Audiology, 22(2). 316-320.

Reinemer, M. \& Hood, J. (1999) Untreated Hearing Loss Linked to Depression, Social Isolation in Seniors. Audiology Today 11(4).

Shoham, N., Shoham, N., Lewis, G., Lewis, G., Favarato, G., Favarato, G.,...Cooper, C. (2019) Prevalence of anxiety disorders and symptoms in people with hearing impairment: A systematic review. Social Psychiatry \& Psychiatric Epidemiology 54(6). 649-660.

Southall, K., Gagné, J. \& Jennings, M. (2010) Stigma: A negative and a positive influence on help-seeking for adults with acquired hearing loss. International Journal of Audiology, 49(11). 804-814.

Stevenson, J., Pimperton, H., Kreppner, J., Worsfold, S, Terlektsi, E. \& Kennedy, C. (2017) Emotional and Behaviour Difficulties in Teenagers with permanent childhood hearing loss. International Journal of Pediatric Otorhinolaryngology 101. $186-195$

Sydlowski, S. (2018) OTC Hearing Aids Are Coming - But They're Not for Everyone. Senior Health, https://health.clevelandclinic.org/otc-hearing-aids-are-comingbut-theyre-not-for-everyone/

The Food and Drug Reauthorization Act, Public Law 115-52. Section 709. (2017)

Uchida, Y., Sugiura, S., Nishita, Y., Saji, N., Sone, M., \& Ueda, H. (2019) Age-related 
hearing loss and cognitive decline - The potential mechanisms linking the two. Auris Nasus Larynx 46. 1-9.

United States Department of Health \& Human Services. Center for Disease Control \& Prevention. The National Center for Health Statistics. National Health Interview Survey, 2011. Ann Arbor, MI: ICPSR. 01-03-2017.

Wallhagen, M. (2009) The Stigma of Hearing Loss. The Gerontologist 50(1) 66-75.

Wang, J., Sung, V., le Clercq, C., Burt, R., Carew, P., Liu, R.,...\& Wake, M. (2019) High prevalence of slight and mild hearing loss across mid-life: a crosssectional national Australian study. Public Health 168. 26-35.

Xiang, X., An, R., Kang, S., Stagg, B., \& Ehrlich, J. (2020) Disability type, depression and antidepressants use among older adults in the United States. Aging and Mental Health 24(1) 27-34.

Zaidman-Zait, A., Most, T., Tarrasch, R., Haddad-eid, E., \& Brand, D. (2016) The impact of Childhood hearing loss on the family: Mothers' and fathers' stress and coping resources. Journal of Deaf Studies \& Deaf Education 21(1). 23-33. 